\title{
Adolescent Social Communication Through Smartphones: Linguistic Features of Internalizing Symptoms and Daily Mood
}

\author{
Elizabeth A. McNeilly ${ }^{1}$ \\ Kathryn L. Mills ${ }^{1,2}$ \\ Lauren E. Kahn ${ }^{1}$ \\ Ryann Crowley ${ }^{1}$ \\ Jennifer H. Pfeifer ${ }^{1}$ \\ Nicholas B. Allen ${ }^{1}$ \\ 1. Department of Psychology, University of Oregon, Eugene, USA \\ 2. PROMENTA Research Center, Department of Psychology, University of Oslo, Norway
}

\begin{abstract}
Author Note
Correspondence: Elizabeth A. McNeilly, Department of Psychology, University of Oregon, 1227 University of Oregon, Eugene, OR 97403

emcneill@uoregon.edu

Funding: This work was supported by the National Institute of Mental Health (R01-MH107418; PI: Pfeifer). KLM was supported by the Research Council of Norway (RCN) grant number 288083.

Declarations of Conflicting Interests: Nicholas Allen, Lauren Kahn, and Ryann Crowley hold equity interests in Ksana Health Inc., a company that has the sole commercial license for certain versions of the Effortless Assessment Research System (EARS) mobile phone application and some related EARS tools.

Keywords: adolescents, smartphones, social, linguistics, internalizing, mood
\end{abstract}




\title{
ADOLESCENT SOCIAL COMMUNICATION
}

\begin{abstract}
The increasing use of smartphone technology by adolescents has led to unprecedented opportunities to identify early indicators of shifting mental health. This intensive longitudinal study examined the extent to which differences in mental health and daily mood are associated with digital social communication in adolescence. In a sample of 30 adolescents (ages 11-15 years), we analyzed 22,152 messages from social media, email, and texting across one month. Lower daily mood was associated with linguistic features reflecting self-focus and reduced temporal distance. Adolescents with lower daily mood tended to send fewer positive emotion words on a daily basis, and more total words on low mood days. Adolescents with lower daily mood and higher depression symptoms tended to use more future focus words. Dynamic linguistic features of digital social communication that relate to changes in mental states may represent a novel target for passive detection of risk and early intervention in adolescence.
\end{abstract}




\section{ADOLESCENT SOCIAL COMMUNICATION}

Adolescence is a key period of development for socioemotional learning, as social and affective processes undergo significant change during this time (Crone \& Dahl, 2012; Dahl et al., 2018). An orientation towards peer relationships in an increasingly complex social landscape, alongside a heightened sense of social sensitivity, are hallmark characteristics of adolescence (Nelson et al., 2016; Somerville, 2013). Social relationships also especially impact the mental health and mood of adolescent girls, as they may be particularly reliant on social relationships for emotional support and identity formation, making them potentially more vulnerable to interpersonal stress (Rose \& Rudolph, 2006; Rudolph \& Hammen, 1999). Further, girls are twice as likely than boys to have an anxiety or mood disorder emerge during adolescence (Hankin \& Abramson, 2001; Kessler et al., 2003), making adolescence a heightened period of vulnerability wherein US data indicates that fifty-percent of all cases of mental illness onset by the age of 14 (Kessler \& Wang, 2008).

In tandem with the rise of social relationships and risk for mental health disorders in adolescence, the increasing role of smartphone technology in the everyday lives of adolescents has led to unprecedented opportunities for social interaction, engagement, and expressing one's social identity (Odgers \& Jensen, 2020; Rideout \& Robb, 2018). Social communication on smartphones is one of the primary ways these daily interpersonal experiences unfold. Recent research has found that fluctuations in adolescent social communication may play a role in the link between stressful life events and internalizing symptoms (Rodman et al., 2021), and that early adolescence (11-13 years old for girls and 14-15 years old for boys) may represent a developmentally sensitive period for the impact of social media on life satisfaction (Orben et al., 2022). Further, approximately 95 percent of adolescents in the U.S. own or have access to a smartphone (Pew Research Center, 2018), and texting has recently been found to be the most preferred method by adolescents for communicating with friends (Rideout \& Robb, 2018). Recent advancements in technology now enable passive collection of digital smartphone communication data in real-time (Lind et al., 2018). Together, these technological developments provide a naturalistic and highly salient interpersonal context through which the pathways and individual differences that determine the mental health and mood of adolescents may be explored.

\section{Linguistic Markers of Internalizing Psychopathology}




\section{ADOLESCENT SOCIAL COMMUNICATION}

First-Person Pronouns. Self-focused attention, the tendency to excessively focus on the self (Mor \& Winquist, 2002), is a cognitive bias that has been linked to increased use of firstperson pronouns, depression, and anxiety (Brockmeyer et al., 2015; Sonnenschein et al., 2018). Further, self-focused attention is theorized to manifest in the first-person pronoun use and may explain the emergence of first-person pronoun use as a potential marker of depression and anxiety symptoms. A recent meta-analysis found that greater use of first-person pronouns is positively correlated with depressive symptoms in adults (Edwards \& Holtzman, 2017). This association has also been observed in multiple languages, including Spanish and German, and in different settings including online discussion boards and interviews (Ramirez-Esparza et al., 2008; Zimmermann et al., 2013). A study of undergraduates found that individuals with current symptoms of depression above a clinically significant threshold indeed used more of the firstperson pronoun, "I," than never-depressed individuals (Rude et al., 2004). Furthermore, higher first-person pronoun use has also been found to prospectively predict depressive symptoms 8 months later, in a clinical sample of adults ages 19-59 years (Zimmermann et al., 2017). This finding suggests that higher use of first-person pronouns may, in part, reflect an individual difference that precedes depression. Moreover, temperamental correlates of trait-like mood may also be related to first person pronoun use. In a multi-lab study of 4,754 participants, higher levels of first-person pronoun use was robustly associated with the personality trait of negative emotionality, even when controlling for depression symptoms (Tackman et al., 2019). However, the extent to which the propensity to use first-person pronouns is reflective of an individual's relatively stable mood, as compared to being influenced by fluctuations in mood, requires further research to determine. Nonetheless, understanding the dynamics of the association between the use of first-person pronouns and daily mood has the potential to serve as an in vivo, linguistic marker of mental health.

Emotion Words. Depression and anxiety have been characterized in part by cognitive biases towards negative information and negative schemas or perspectives (Everaert et al., 2018; Haaga \& Beck, 1995; Hamilton \& Abramson, 1983). Further, an excess of negative affect and a deficiency of positive affect have been proposed as underlying the emotion dysregulation of depression and anxiety (Gross \& Jazaieri, 2014; Hofmann et al., 2012) As such, the use of negative and positive emotion words are another language feature that has been assessed in relation to internalizing symptoms. For instance, individuals with current, clinically significant 


\section{ADOLESCENT SOCIAL COMMUNICATION}

symptoms of depression used more negative emotion words than never-depressed individuals (Rude et al., 2004). A study in the Netherlands aimed to replicate the Rude et al. (2004) study and found that depressed and non-depressed psychiatric outpatients, used greater negative emotion words and fewer positive emotion words than healthy controls (Molendijk et al., 2010). This finding suggests that these linguistic patterns may indicate transdiagnostic distress; however, other research has led to mixed findings as to what degree affective language and firstperson pronouns are associated with specific internalizing disorders or more generally with negative mood. One study exploring these linguistic features found that depression symptoms were associated with first-person pronouns, but not with higher negative or lower positive emotion word use (Bernard et al., 2016). Another study in young adults found that, within a given day, negative and positive emotion word use on Facebook was not associated with one's self-report of negative or positive emotion (Kross et al., 2019). Taken together, further research is warranted to investigate whether the use of these linguistic features in naturalistic communication are associated with differences in mental health, potentially serving as a marker of cognitive or affective vulnerability to depression or anxiety.

\section{The Present Study}

Despite growing empirical evidence in this area of research, large gaps in the literature remain. First, identifying linguistic features detectable in naturalistic social communication that are associated with mental health symptoms could inform the development of novel early interventions. Currently, however, the context of the language tasks within existing studies varies from writing tasks on various topics, semi-structured interviews, unstructured speaking prompts, online forums, and social media posts, but few have explored quintessential forms of digital social communication, such as smartphone messaging. Perhaps the link between linguistic features and mental health is dependent upon the saliency of the context and the utility of the communication itself. Daily digital communication through text messages and social media is of particular importance in the social world of adolescents. Based on a recent study of adolescents, three primary factors emerged to describe why teens communicate through smartphones in particular: to facilitate social connection, to link online and offline experiences, and to extend one's identity beyond the offline environment (Moreno et al., 2020). These highly salient social processes may relate to language in such a way that uniquely represents or contributes to one's mental health or mood, further providing a potential source of passive risk identification. 


\section{ADOLESCENT SOCIAL COMMUNICATION}

Second, it is unknown whether these linguistic features manifest as a relatively stable trait within an individual or as a dynamic indicator of information processing that fluctuate alongside changes in mood and experiences. Self-focused attention, which may be manifested through the use of first-person pronouns, has been found to differentially relate to mental health outcomes in negative versus positive experiences (Mor \& Winquist, 2002). For instance, greater use of firstperson pronouns in negatively valenced contexts has been linked to symptoms of depression and anxiety (Brockmeyer et al., 2015). Experimentally-induced momentary states of negative affect have also been associated with greater use of negative emotion words, but not first-person pronouns (Bernard et al., 2016). These findings demonstrate that certain linguistic features may affect emotional states in addition to being affected by these states. This complex interaction between language and emotion has been demonstrated in the domain of emotion regulation. Effective emotion regulation, as indicated by lower negative affect, has been prospectively linked to linguistic features characteristic of psychological distance (i.e., low first-person pronouns, low present focus words) (Nook et al., 2017) and distanced self-talk (Orvell et al., 2021). Additionally, when experimentally-manipulated, use of psychologically-distanced language led to more effective emotion regulation (Nook et al., 2017; Orvell et al., 2021). Further, the ability to use linguistic distancing during emotion regulation is present from age 10 through young adulthood (Nook et al., 2019); however, this has not been assessed in naturalistic contexts. Taken together, linguistic features that are dynamically related to changes in mental states may be particularly good early indicators of risk and targets for novel intervention, while linguistic features that have a stable association with low mood or negative mental health outcomes may represent an individual difference in vulnerability.

Third, there are few studies examining the association between naturalistic peer-directed social communication and mental health in the time that it is arguably most needed: adolescence. This period of development is characterized in part by vast socioemotional learning and changes in mental health, both of which may be manifested in and influenced by social communication. Previous research on online social communication has mostly been conducted in adult samples, with the exception of one study of adolescents, which revealed that, over the course of four days, higher frequencies of negative emotion words sent via mobile devices were associated with higher internalizing symptoms and anxious depression (Underwood et al., 2015). Furthermore, digital social communication may have a bidirectional relationship with aspects of 


\section{ADOLESCENT SOCIAL COMMUNICATION}

socioemotional development during adolescence, wherein the communication reflects aspects of this development while also serving as a conduit for these processes to evolve. For instance, text messaging may contribute to adolescents navigating key developmental milestones, such as orienting towards peers, gaining independence from parents, and forming and expressing one's identity (Ehrenreich et al., 2019; Spies Shapiro \& Margolin, 2014). Identifying associations between language in social communication and mental health in youth is one facet in understanding how these core developmental milestones may be affected by changes in mental states.

The present study was well-situated to address these gaps in the literature. Critically, this study utilized a between- and within-subject design in a sample of adolescents. This study design allowed us to explore the extent to which between-subject differences in mental health and mood, as compared to relatively momentary mood states, contributed to associations with language in adolescence.

\section{Study Aims and Hypotheses}

In this preregistered, intensive longitudinal study, we assessed the extent to which linguistic features expressed through daily digital communication differentially relate to between-subject differences in average daily mood, depression and anxiety symptoms, and within-subject changes in daily mood, amongst adolescent girls. (See osf.io/utsed for preregistration.) We aimed to not only be able to identify linguistic markers of depressive and anxiety symptoms in adolescent girls, but also changes in subjective mood, which may inform novel preventative interventions to improve adolescent mental health. Further, by investigating daily language use in a digital social context within a developmental sample, we also aimed to elucidate potential pathways manifested in this form of social engagement that relate to developmental processes underway.

Specifically, we analyzed linguistic features from all smartphone keyboard data linked to social communication, which was classified by any text entered into social media and text messaging apps over the course of one month using a novel tool, the Effortless Assessment Research System (Lind et al., 2018). In addition, we collected ecological momentary assessment of daily mood, which enabled us to track changes in language with changes in subjective mood. We were interested in linguistic features associated with self-focused attention (i.e., first-person pronouns) and emotion words (i.e., negative and positive), given their connection to depression 


\section{ADOLESCENT SOCIAL COMMUNICATION}

and anxiety in previous studies. We preregistered the following confirmatory hypotheses: 1) Higher depression and anxiety symptoms would be associated with higher daily use of firstperson pronouns; 2) Higher depression and anxiety symptoms would be associated with higher daily use of negative emotion words. These hypotheses were conceptualized as confirmatory given that previous research has investigated similar associations between these linguistic features and depression and anxiety symptoms. The present study was designed to not only test these hypotheses, but also generate related hypotheses to be tested in future research. As such, the following linguistic features were considered exploratory. First, we were interested in temporal characteristics (i.e., past, present, and future focus words) as a potential marker of varying degrees of psychological distance in social communication. Informed by theory on psychological distancing (Bruehlman-Senecal \& Ayduk, 2015; Nook et al., 2017), we explored the extent to which the use of present, past, and future focus words were negatively associated with depression and anxiety symptoms. Second, as negative and positive sentiment may reflect distinct mental states, we were interested in whether lower use of positive emotion words would be associated with higher depression and anxiety symptoms. Third, since each linguistic feature was operationalized as a proportion of total daily words, daily words was included a separate linguistic feature of interest. Daily word count may serve as a potential dynamic indicator of the influence one's mental state may have on the extent of social engagement, or withdrawal. Daily word count and positive emotion words were identified post-hoc, and thus are non-preregistered exploratory linguistic features. Taken together, we explored the extent to which within- and between-subject differences in daily mood were associated with these seven linguistic features (first-person pronouns, positive and negative emotion words, past, present and future focus words, and daily word count), in addition to their associations with depression and anxiety symptoms.

\section{Methods}

\section{Sample}

The present study's sample is drawn from a larger multi-wave, longitudinal study known as the Transitions in Adolescent Girls (TAG) Study (R01 MH107418, PI: Pfeifer; Barendse et al., 2020). The sample included 30 adolescents (100\% female) aged $11-15$ years old ( $\mathrm{M}=14.51$, $\mathrm{SD}=1.23$; Table 1). Participants described themselves as non-Hispanic/Latinx/Chicanx white (63.3\%), Hispanic/Latinx/Chicanx white (10.0\%), Hispanic/Latinx/Chicanx multiracial (6.7\%), 


\section{ADOLESCENT SOCIAL COMMUNICATION}

and non-Hispanic/Latinx/Chicanx multiracial (20.0\%). Annual household income ranged from below $\$ 25,000$ (3.3\%), \$25,000-\$40,000 (13.3\%), \$40,000-\$75,000 (26.7\%), \$75,000-\$100,000 (16.7\%), and over $\$ 100,000$ (36.7\%). Participants were primarily recruited through school districts in Eugene and Springfield, Oregon, with some participants recruited from community flyers, recruitment events, and individuals who registered on the lab/department's website. As part of the recent wave of the larger study, participants were asked if they were interested in joining a sub-study on adolescent smartphone behaviors. As recruitment for the study began before the COVID-19 pandemic, and continued thereafter, we decided to restrict the study sample to only participants who had enrolled in the study and completed the 1 month of data collection prior to the local COVID-19 stay-in-place orders for Eugene and Springfield, Oregon. Informed consent and assent were obtained from all parents and participants, respectively. The Institutional Review Board of the University of Oregon approved all study procedures and materials.

\section{Procedures}

Data Collection. During the first study session of the participant's current wave of a larger multi-year longitudinal study (Barendse et al., 2020), participants downloaded the Effortless Assessment Research System (EARS) application (Lind et al., 2018) to their Android or iOS smartphones Participant enrollment dates spanned from June 26, 2019 to February 5, 2020. Participants were advised to keep the app interface installed on their phones until their second study session, which was scheduled to occur approximately 4 weeks later. Between the study sessions, participants were instructed to use their phone as they normally would. Approximately 4 weeks later, participants returned to the laboratory for their next session, during which they uninstalled the EARS app from their phones and completed self-report questionnaires assessing depression and anxiety symptoms (see measures below). All keyboard strokes entered on the participant's smartphone were collected by a key logger. This was achieved by installing a custom keyboard on iOS phones, and by logging the currently installed keyboard on Android phones. These data were encrypted, stored on a secure server in the cloud, and then subsequently downloaded and decrypted by the research team. Further details on the engineering, encryption, and secure storage of the data can be found in Lind et al. (2018).

Data Preparation. An algorithm was applied to the data that converted the individual keyboard strokes into complete words and messages. Each message had a timestamp for the start 


\section{ADOLESCENT SOCIAL COMMUNICATION}

and end of the message, along with the app within which the message was entered. Each app was classified as either SMS, social media, email, or non-communication (See Appendix B). App categories were based on the app's stated primary purpose. For instance, Instagram was classified as social media, despite having a direct messaging feature, because of the app's category within the Apple app store and Google Play store. Conversely, apps such as WhatsApp were classified as SMS because its stated explicit purpose is messaging, not a social media platform. Lastly, apps were classified as non-communication if text communication is not a primary or explicit purpose of the app (e.g., YouTube, Google, Pinterest, music streaming). Given that the aims of the study were centered on questions related to social communication, only text data from social communication apps (e.g., SMS, email, social media) were analyzed in this study.

For this study, we focused only on the concurrent association between mood and linguistic features. For this reason, only text data that temporally matched with a participant's daily ecological momentary assessment (EMA) response was used. The EMA question assessed mood "over the last day," and was received by each participant at 8am, and expiring at 11:59pm (see measures below). When participants are introduced to the EMA portion of the study, they are asked to answer the EMA when it was received at 8am and to answer in regard to the previous day. As such, text data from the previous calendar date was considered the concurrent text data.

Herein, we report how we determined our sample size, all data exclusions, all manipulations, and all measures in the study. All methodological decisions were made prior to analysis, despite some decisions not being outlined explicitly in the preregistration. One exception to this was a revision of the inclusion criteria in response to peer-review feedback. See Supplement A for further details.

\section{Measures}

Text Data. Text data was processed by the Linguistic Inquiry and Word Count (LIWC) 2015 software, which calculates the proportion of words in a given message that coincide with specific linguistic categories (e.g., first-person pronouns, present focus words, negative emotion) (Pennebaker et al., 2015). LIWC has been used in studies of online language as advances in technology have made that type of data more available. For instance, LIWC has been used to study linguistic features from text messages (Glenn et al., 2020), Facebook (Eichstaedt et al., 


\section{ADOLESCENT SOCIAL COMMUNICATION}

2018), Reddit (Pavalanathan \& De Choudhury, 2015), and Twitter (O’Dea et al., 2017). To arrive at the daily linguistic feature proportions, first each message was analyzed using LIWC, which calculated the proportion of total words in a message from a given linguistic category. For instance, a score of 10 for a linguistic category, such as first-person pronouns, indicates that $10 \%$ of the words in that message were first-person pronouns. Using both the proportion and the total number of words in a given message, proportions were converted to absolute word counts by message. Lastly, daily proportions of linguistic categories were a ratio of total number of words within a category to the total words that day for an individual. As such, each linguistic category is independent of the number of words entered on a given day, which controls in part for individual differences in communication quantity. Total daily words were analyzed as a separate linguistic category of interest. Of the 403 daily observations, we applied a minimum threshold of 30 words for a given daily observation to be included, which resulted in 324 daily observations, or $80 \%$ of the original sample. The minimum of 30 words per day was identified through plotting the bivariate distributions of daily word count and the daily proportion of the linguistic feature, and estimating the quantity of daily words at which the daily proportion appeared to cease systematically producing outliers. Next, we applied a minimum threshold of 3 daily observations, as 3 is the minimum number of within-subject observations recommended to conduct longitudinal analyses (Singer \& Willett, 2003). See Supplement A for further details regarding the implementation of our inclusion criteria. This criterion resulted in 311 daily observations, or $77 \%$ of the original sample. Linguistic features were analyzed at the day level to temporally align with the day-level reporting of mood. The text field containing the message was removed from the data set following linguistic feature scoring in order to preserve confidentiality.

One linguistic category, absolutist words, was assessed using a custom dictionary that was imported into the LIWC software, and processed in the same way as the LIWC internal default dictionaries for all other word categories. This absolutist dictionary was based on the 19word dictionary of absolutist words created by Al-Mosaiwi \& Johnstone (2018). The daily proportion of absolutist words had a zero-inflated distribution which introduced problems in conjunction with the current analysis techniques and as such, would require a markedly different approach to data analysis procedure. Thus, we are not analyzing this category at this time. 


\section{ADOLESCENT SOCIAL COMMUNICATION}

Depression Symptoms. We measured depressive symptoms with the Center for Epidemiologic Studies Depression Scale for Children (CES-DC; Faulstich et al., 1986; Weissman et al., 1980). The CES-DC is a 20-item self-report measure of depression symptoms with each response ranging from 0 ("Not at all") to 3 ("A lot"), and total scores ranging from 060. Scores of 15 and higher indicate clinical significance. Depression symptoms were a betweensubjects variable, as they were only assessed at one time point in the study.

Anxiety Symptoms. We measured anxiety symptoms as a between-subjects variable (i.e., assessed once in the study) with the Screen for Child Anxiety Related Disorders - Revised (SCARED-R; Muris et al., 1998) as a measure of anxiety symptoms. The brief version of the SCARED-R screens for DSM-5 anxiety-related symptomatology through a 5-item multidimensional anxiety scale (Birmaher et al., 1999). Participants are asked to choose "the answer that seems to describe you now" on a scale of 0 ("Not True or Hardly Ever True") to 2 ("Very True or Often True"), with total scores ranging from 0-10. A score of 3 or higher indicates clinical significance.

Mood. We measured daily mood through an EMA questionnaire that was sent to each participant's phone once a day at 8:00am and expired at 11:59pm. Participants were asked: "In general, how have you been feeling over the last day?" Scores were provided on a sliding visual analog scale ranging from 0-100 (very negative to very positive).

\section{Statistical Analysis}

To disaggregate within- and between-subject effects of internalizing symptoms and mood on linguistic features, multilevel models (MLM) were used. MLM analysis is suitable for longitudinal data wherein participants each have multiple observations due to repeated measurement. In this study, text data and mood were repeatedly measured each day. A withinsubjects variable of daily mood (i.e., within-subjects mood) was calculated by centering daily mood scores on the participant's average mood over the entire study period. A between-subjects variable of mood (i.e., between-subjects mood) was calculated by centering daily mood on the average mood over the entire study period across all participants (Enders \& Tofighi, 2007). Depression and anxiety symptoms measured at the end of the study also represented betweensubject sources of variance as they were only measured once in the study. Multiple imputation was used to estimate depression and anxiety symptoms for two participants with missing symptom-level data by utilizing internalizing disorder diagnostic data as predictors of the 


\section{ADOLESCENT SOCIAL COMMUNICATION}

missing data in the imputation model (Bono et al., 2007; Hayati Rezvan et al., 2015; Lee \& Simpson, 2014). The linear regression imputation was conducted using the 'mice' package in $\mathrm{R}$ (R Core Team, 2019; van Buuren \& Groothuis-Oudshoorn, 2011). Predictions for missing values were based on DSM-IV diagnostic-level data from internalizing disorders within the Kiddie Schedule for Affective Disorders and Schizophrenia (K-SADS) assessment interview, including generalized anxiety, major depressive disorder, social anxiety, post-traumatic stress disorder, separation anxiety, anxiety not otherwise specified, and depression not otherwise specified. No other data was imputed. Additionally, we centered age as a covariate so that the variable would have an interpretable, meaningful zero.

We tested four primary types of models for each linguistic feature of interest. First, to test our confirmatory hypotheses, we tested the main effects of depression symptoms and anxiety symptoms on linguistic features in separate models. Second, we explored the associations between linguistic features and mood by testing the main effects of within- and between-subjects mood on each linguistic feature, separately and also in the same model. Third, we tested the interaction effect between within- and between-subjects mood on each linguistic feature. Fourth, we added depression and anxiety symptoms separately to the mood interaction model in order to control for between-subject differences in these internalizing symptoms. Given the age range of 11-15 years, we also included age in our final, most complex models. Age was not declared a primary effect of interest. Nonetheless, there is a dearth of comparable developmental studies in the literature, and thus, we deemed it valuable to report the associations with age for the purpose of informing future research. All models used a random intercept for participant in order to account for multiple observations per participant. Models were estimated in R 3.6.2 (R Core Team, 2019) with the 'Ime4' package version 1.1-23 (Bates et al., 2015) using the restricted maximum likelihood estimation (REML), which is recommended with small sample sizes (Luke, 2017; Peugh, 2010), such as those below 50 (McNeish, 2017).

We used likelihood ratio tests to determine goodness of fit when comparing the null model (i.e., unconditional means model) to simple models of main effects and to full models with a within- and between-subject mood interaction term. Main effects models that were a better fit than the null model were then built with increasing complexity, with the addition of variables in order of increasing within-subject stability (i.e., within-subjects mood followed by between-subjects mood followed by depression and anxiety symptoms followed by age). This 


\section{ADOLESCENT SOCIAL COMMUNICATION}

enabled us to test the degree to which daily, dynamic within-subject changes in mood better accounted for daily, dynamic within-subject changes in language as compared to variables with less intra-individual variability, such as depression or anxiety symptoms. The null model was first tested against within-subjects mood, followed by between-subjects mood, the main effects of within- and between-subjects mood, the interaction of within- and between-subjects mood, main effects of depression or anxiety symptoms, and main effect of age. If within- or betweensubjects mood, or a more complex model of the two variables was significant, hierarchical models were further added to by depression or anxiety symptoms, and age. Akaike Information Criterion (AIC) values were used to assess the relative model fit. Criteria for the best fit model is having the lowest AIC and passing a likelihood ratio test $(\mathrm{p}<.05)$ when compared to the null model and the next simplest model, if the next simplest model is not the null model. AIC values were used to compare any non-nested models. All model comparison statistics are presented in Table S1 in Supplement B available online. Effect size is reported as the standardized coefficient estimate, along with the $95 \%$ confidence interval, from the best fit model.

\section{Results}

\section{Descriptive Statistics}

Descriptive statistics for the sample characteristics (i.e., age, gender, race, ethnicity, annual household income), internalizing symptoms, mood, and linguistic features are displayed in Table 1. The intraclass correlation coefficient (ICC) for each linguistic feature is also presented in Table 1. The most common SMS apps were iPhone Messages, Android Messages, Facebook Messenger, and WhatsApp. Top social media apps included Facebook, Instagram, Snapchat, and TikTok. Lastly, the most common email apps were Gmail and Apple Mail.

Table 1. Descriptive Statistics and ICCs of Dependent Variables

\begin{tabular}{lcccc}
\hline \multicolumn{1}{l}{ Age } & $N=30(\%)$ & $M$ & $S D$ & ICC \\
Gender & & 14.51 & 1.23 \\
$\quad$ Female & $30(100 \%)$ & & \\
Race and Ethnicity & & & \\
$\quad$ non-Hispanic/Latinx/Chicanx white & $19(63.3 \%)$ & & \\
$\quad$ Hispanic/Latinx/Chicanx white & $3(10.0 \%)$ & & \\
\hline
\end{tabular}




\section{ADOLESCENT SOCIAL COMMUNICATION}

\begin{tabular}{|c|c|c|c|c|}
\hline multiracial Hispanic/Latinx/Chicanx & $2(6.7 \%)$ & & & \\
\hline multiracial & $6(20.0 \%)$ & & & \\
\hline \multicolumn{5}{|l|}{ Annual Household Income } \\
\hline Up to $\$ 25,000$ & $1(3.3 \%)$ & & & \\
\hline$\$ 25,000$ to $\$ 40,000$ & $4(13.3 \%)$ & & & \\
\hline$\$ 40,000$ to $\$ 75,000$ & $8(26.7 \%)$ & & & \\
\hline$\$ 75,000$ to $\$ 100,000$ & $5(16.7 \%)$ & & & \\
\hline Over $\$ 100,000$ & $11(36.7 \%)$ & & & \\
\hline "Don’t know" & $1(3.3 \%)$ & & & \\
\hline Days with Text $(\mathrm{N})$ & & 23.57 & 6.39 & \\
\hline Days with EMA (N) & & 18.43 & 10.81 & \\
\hline Days Overlapping Text \& EMA & & 10.37 & 7.40 & \\
\hline Depression Symptoms & & 18.70 & 12.56 & \\
\hline Anxiety Symptoms & & 1.80 & 1.63 & \\
\hline Mood (Average) & & 68.52 & 22.12 & \\
\hline \multicolumn{5}{|l|}{ Linguistic Features } \\
\hline First-Person Pronouns & & 7.94 & 2.21 & 0.34 \\
\hline Positive Emotion Words & & 5.85 & 1.53 & 0.17 \\
\hline Negative Emotion Words & & 2.12 & 0.89 & 0.15 \\
\hline Word Count & & 288.95 & 237.42 & 0.40 \\
\hline Past Focus Words & & 3.11 & 0.91 & 0.12 \\
\hline Present Focus Words & & 13.32 & 1.91 & 0.15 \\
\hline Future Focus Words & & 1.94 & 0.79 & 0.19 \\
\hline
\end{tabular}

Note: $M=$ Mean; $S D=$ Standard Deviation; ICC=Intraclass Correlation Coefficient.

Linguistic features are daily average proportion of total words (i.e., $2=2 \%$ of daily words).

\section{First-person Pronouns}

We did not observe evidence in support of the hypothesis for a main effect of depression or anxiety symptoms on first-person pronouns. Within-subjects mood was associated with daily proportion of first-person pronouns $\left[\chi^{2}(1)=6.83, \mathrm{p}<.01\right]$. Higher within-subjects mood was associated with lower daily proportion of first-person pronouns $(\beta=-.12,95 \% \mathrm{CI}[-.21,-.03]$; Figure 1). Hierarchical model comparisons revealed that between-subjects mood did not relate to 


\section{ADOLESCENT SOCIAL COMMUNICATION}

first-person pronouns ( $\beta=-.20,95 \%$ CI $[-.46, .06])$, and adding between-subjects mood to the model, along with within-subjects mood, did not improve the fit $\left[\chi^{2}(1)=2.41, \mathrm{p}=.12\right.$; Table 2]. Neither depression nor anxiety symptoms nor age improved the model fit. (See Table S1 in the Supplement B available online for all model comparison statistics.)

A.

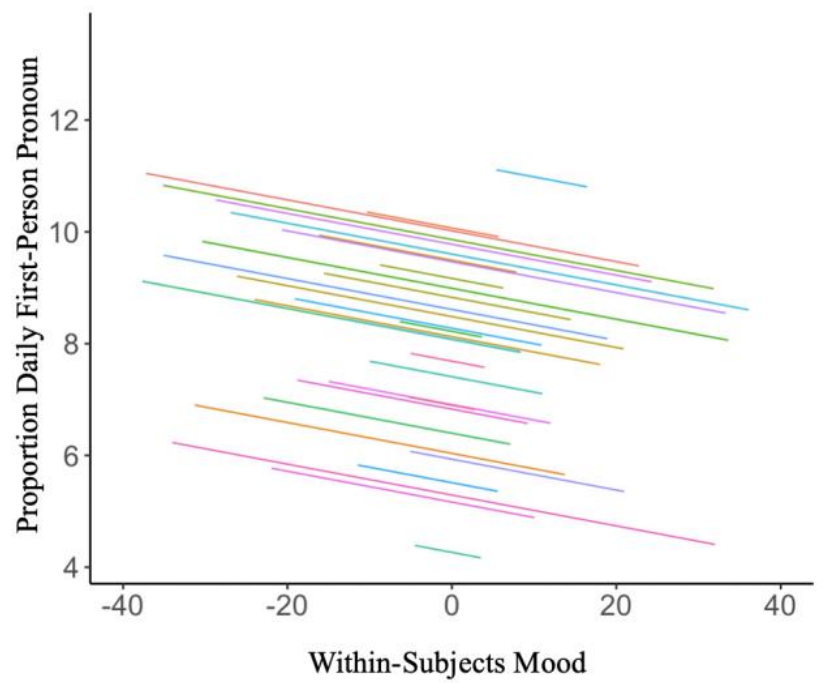

B.

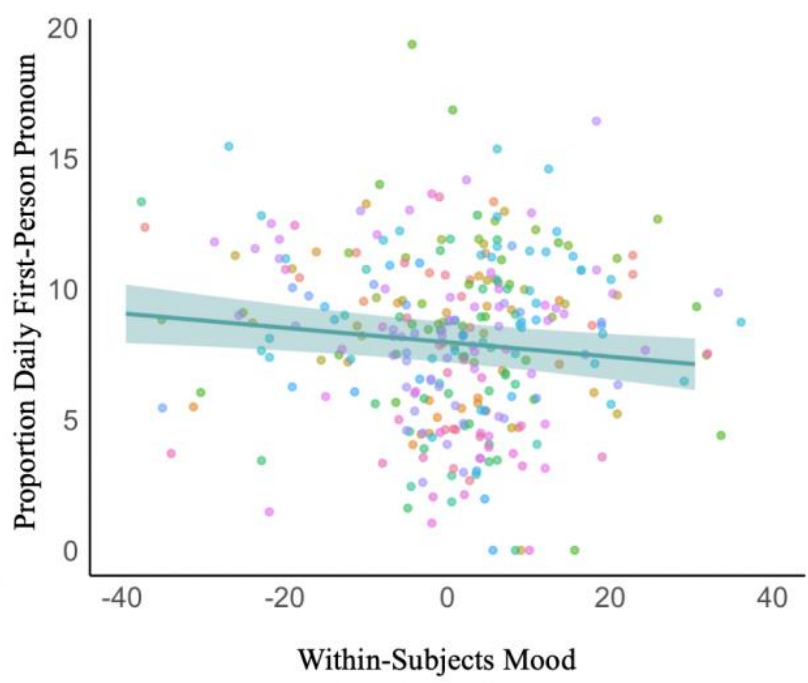

Figure 1. Figures 1A and 1B above depict the association between within-subjects mood and proportions of daily first-person pronouns. Within-subjects mood is person-centered at zero. Figure 1A depicts individual lines representing each participant's predicted regression line (random intercept, fixed slope) for this association. Figure 1B depicts the distribution of within-subjects mood and proportions of daily first-person pronouns. The solid line represents the overall predicted regression line of this association, and the shaded region represents the $95 \%$ confidence interval. Reporting a more positive mood compared to one's average mood was associated with lower proportion of daily first-person pronouns.

Table 2. Results of Confirmatory Hypotheses: Main Effects and Best Fit Model

\begin{tabular}{|c|c|c|c|c|c|c|c|c|}
\hline \multirow[t]{2}{*}{ Model } & \multicolumn{4}{|c|}{ Main Effects } & \multicolumn{4}{|c|}{ Best Fit Model } \\
\hline & $\beta$ & $95 \% C I$ & $p$ & AIC & $\beta$ & $95 \% C I$ & $p$ & AIC \\
\hline First-person Pronouns & & & & & & & & 1552.1 \\
\hline Within-subjects Mood & -.12 & {$[-.21,-.03]$} & .009 & 1552.1 & -.12 & {$[-.21,-.03]$} & .009 & \\
\hline Between-subjects Mood & -.20 & {$[-.46, .06]$} & .14 & 1556.5 & .10 & L & + & \\
\hline Within-subjects $\mathrm{x}$ & .00 & {$[-.11, .10]$} & .93 & 1553.6 & - & - & - & \\
\hline Between-subjects Mood* & & & & & & & & \\
\hline Depression Symptoms & .09 & {$[.00, .42]$} & .43 & 1558.2 & 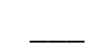 & $\ldots$ & 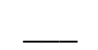 & \\
\hline Anxiety Symptoms & -.02 & {$[-.23, .19]$} & .85 & 1558.9 & - & - & $\bar{\tau}$ & \\
\hline Age & .11 & {$[-.11, .32]$} & .34 & 1557.9 & - & - & {[} & \\
\hline
\end{tabular}




\begin{tabular}{lccccccc}
\hline Negative Emotion Words & & & & & & & \\
$\quad$ Within-subjects Mood & -.04 & {$[-.24, .13]$} & .48 & 1192.5 & - & - & - \\
Between-subjects Mood & -.08 & {$[-.29, .12]$} & .44 & 1192.3 & - & - & - \\
Within-subjects x & .08 & {$[-.04, .20]$} & .18 & 1194.0 & - & - & - \\
Between-subjects Mood* & & & & & & & \\
Depression Symptoms & .00 & {$[-.17, .18]$} & .93 & 1193.0 & - & - & - \\
Anxiety Symptoms & .04 & {$[-.13, .21]$} & .64 & 1192.7 & - & - & - \\
Age & .11 & {$[-.05, .28]$} & .19 & 1191.2 & - & - & - \\
\hline
\end{tabular}

$\beta=$ Standardized Coefficient Estimate; AIC = Akaike Information Criterion

Table 2 outlines each model organized by dependent variable. In the main effects column, each row of the table represents the main effect of the given independent variable on the dependent variable without any covariates. *The only exception is the interaction model (i.e., Within- x Between-subjects Mood), which contained main effects of within- and between-subjects mood, along with their interaction. The "Best Fit Model" column represents the most complex hierarchical model that also had the lowest AIC and passed the likelihood ratio test with $\mathrm{p}<.05$. A hierarchical model is any model that contains more than one independent variable listed here. Variables with a dash (-) did not contribute to improving the model fit and are thus not included in the "Best Fit Model" column.

\section{Negative Emotion Words}

We did not observe evidence in support of the hypothesis for a main effect of depression or anxiety symptoms on negative emotion words. Further, we did not observe a main effect from within- or between-subjects mood on the daily proportion of negative emotion words. The models including within- or between-subjects mood were not better fits than the null model.

\section{Positive Emotion Words}

We did not observe evidence in support of the hypothesis for a main effect of depression or anxiety symptoms on positive emotion words. Between-subjects mood was associated with daily proportion of positive emotion words $\left[\chi^{2}(1)=5.24, p=.02\right]$. Lower between-subjects mood was associated with lower daily proportion of positive emotion words ( $\beta=.22,95 \%$ CI [.04, .41]; Table 3). Hierarchical model comparisons revealed that this model including only betweensubjects mood was the best fit, and adding within-subjects mood, depression or anxiety symptoms, or age did not improve the model fit.

Table 3. Results of Exploratory Hypotheses: Main Effects and Best Fit Model

\begin{tabular}{ccccccccc}
\hline Model & \multicolumn{4}{c}{ Main Effects } & \multicolumn{3}{c}{ Best Fit Model } \\
\cline { 2 - 9 } & & AIC & $\beta$ & $95 \% C I$ & $p$ & $95 \% C I$ & $p$ & AIC \\
\hline
\end{tabular}




\begin{tabular}{|c|c|c|c|c|c|c|c|c|}
\hline Positive Emotion Words & & & & & & & & 1554.9 \\
\hline Within-subjects Mood & .00 & {$[-.10, .10]$} & .95 & 1560.1 & & & & \\
\hline Between-subjects Mood & .22 & {$[.04, .41]$} & .029 & 1554.9 & .22 & {$[.04, .41]$} & .029 & \\
\hline Within-subjects $\mathrm{x}$ & .01 & {$[-.11, .13]$} & .87 & 1558.9 & $\ldots$ & $\ldots$ & 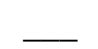 & \\
\hline Between-subjects Mood* & & & & & & & & \\
\hline Depression Symptoms & -.00 & {$[-.18, .17]$} & .96 & 1560.1 & 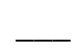 & $\ldots$ & - & \\
\hline Anxiety Symptoms & -.03 & {$[-.20, .14]$} & .70 & 1560.0 & - & 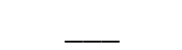 & $\bar{\tau}$ & \\
\hline Age & -.03 & {$[-.20, .15]$} & .77 & 1560.1 & - & $\ldots$ & 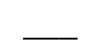 & \\
\hline Past Focus Words & & & & & & & & 1282.10 \\
\hline Within-subjects Mood & .09 & {$[-.02, .20]$} & .10 & 1284.8 & .12 & {$[.00, .23]$} & .045 & \\
\hline Between-subjects Mood & -.009 & {$[-.13, .11]$} & .89 & 1287.4 & -.02 & {$[-.14, .09]$} & .669 & \\
\hline Within-subjects $\mathrm{x}$ & .14 & {$[.01, .26]$} & .034 & 1284.2 & .14 & {$[.01, .26]$} & .034 & \\
\hline Between-subjects Mood* & & & & & & & & \\
\hline Depression Symptoms & -.004 & {$[-.12, .11]$} & .94 & 1287.4 & $\ldots$ & $\ldots$ & $\underline{-}$ & \\
\hline Anxiety Symptoms & .08 & {$[-.04, .20]$} & .20 & 1285.8 & & & & \\
\hline Age & .11 & {$[.00, .22]$} & .051 & 1283.6 & $\overline{.11}$ & {$[.0 \overline{0}, .23]$} & $\overline{.045}$ & \\
\hline Present Focus Words & & & & & & & & 1708.0 \\
\hline Within-subjects Mood & -.06 & {$[-.16, .04]$} & .27 & 1712.0 & & & & \\
\hline Between-subjects Mood & -.21 & {$[-.39,-.04]$} & .029 & 1708.0 & -.21 & {$[-.39,-.04]$} & $\overline{.029}$ & \\
\hline Within-subjects $\mathrm{x}$ & .03 & {$[-.08, .15]$} & .58 & 1710.5 & - & $\ldots$ & $\underline{-}$ & \\
\hline Between-subjects Mood* & & & & & & & & \\
\hline Depression Symptoms & .10 & {$[-.06, .27]$} & .23 & 1711.7 & - & $-\ldots$ & $\underline{ }$ & \\
\hline Anxiety Symptoms & -.02 & {$[-.19, .15]$} & .81 & 1713.2 & 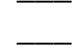 & - & $\overline{1}$ & \\
\hline Age & -.04 & {$[-.21, .12]$} & .61 & 1713.0 & - & - & $\overline{-}$ & \\
\hline Future Focus Words & & & & & & & & 1009.8 \\
\hline Within-subjects Mood & -.07 & {$[-.17, .03]$} & .19 & 1021.0 & & & & \\
\hline Between-subjects Mood & -.27 & {$[-.44,-.10]$} & .007 & 1013.9 & -.17 & {$[-.33 \overline{3,-.01]}$} & $\overline{.063}$ & \\
\hline Within-subjects $\mathrm{x}$ & -.05 & {$[-.17, .07]$} & .39 & 1015.8 & - & $\ldots$ & $\underline{-}$ & \\
\hline Between-subjects Mood* & & & & & & & & \\
\hline Depression Symptoms & .25 & {$[.12, .39]$} & .001 & 1012.2 & .19 & {$[.04, .33]$} & .019 & \\
\hline Anxiety Symptoms & .09 & {$[-.08, .25]$} & .32 & 1021.6 & $\ldots$ & $\ldots$ & $\overline{-}$ & \\
\hline Age & .06 & {$[-.11, .23]$} & .47 & 1022.1 & - & - & $\overline{-}$ & \\
\hline Word Count & & & & & & & & 4426.0 \\
\hline Within-subjects Mood & -.05 & {$[-.13, .04]$} & .26 & 4432.9 & -.03 & {$[-.11, .06]$} & .53 & \\
\hline Between-subjects Mood & -.19 & {$[-.46, .08]$} & .19 & 4432.2 & -.19 & {$[-.44, .07]$} & .17 & \\
\hline Within-subjects $\mathrm{x}$ & .13 & {$[.03, .22]$} & .011 & 4428.4 & .13 & {$[.03, .22]$} & .011 & \\
\hline Between-subjects Mood* & & & & & & & & \\
\hline Depression Symptoms & -.02 & {$[-.25, .20]$} & .83 & 4434.1 & - & $\ldots$ & 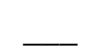 & \\
\hline Anxiety Symptoms & .02 & {$[-.19, .24]$} & .83 & 4434.1 & 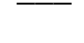 & & 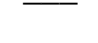 & \\
\hline Age & .22 & {$[.01, .43]$} & .049 & 4429.9 & .22 & {$[.01, .42]$} & .047 & \\
\hline
\end{tabular}

See Table 2 footnote for a description of the formatting and abbreviations used in Table 3.

\section{Past Focus Words}

Within-subjects mood was associated with past focus words $(\beta=.12,95 \% \mathrm{CI}[.00, .23])$.

Hierarchical model comparisons revealed that including the cross-level interaction of within- and between-subjects mood improved the model fit more than a simpler model of main effects $\left[\chi^{2}(1)\right.$ 
$=4.52, \mathrm{p}=.03$ ] (Figure 2). Participants with higher-than-average mood tended to use more past focus words on days when they experienced higher mood relative to their individual average $(\beta=.14,95 \%$ CI $[.01, .26])$. As within-subjects mood decreased for those with higher-thanaverage mood, they texted fewer past focus words in a day. Including age also improved the model fit $\left(\left[\chi^{2}(1)=4.10, p=.04\right]\right.$; Table 3$)$, indicating that older participants used more past focus words on a daily basis $(\beta=.11,95 \% \mathrm{CI}[.00, .23])$. We did not observe a main effect of depression or anxiety symptoms on past focus words, and neither depression nor anxiety symptoms improved the model fit.

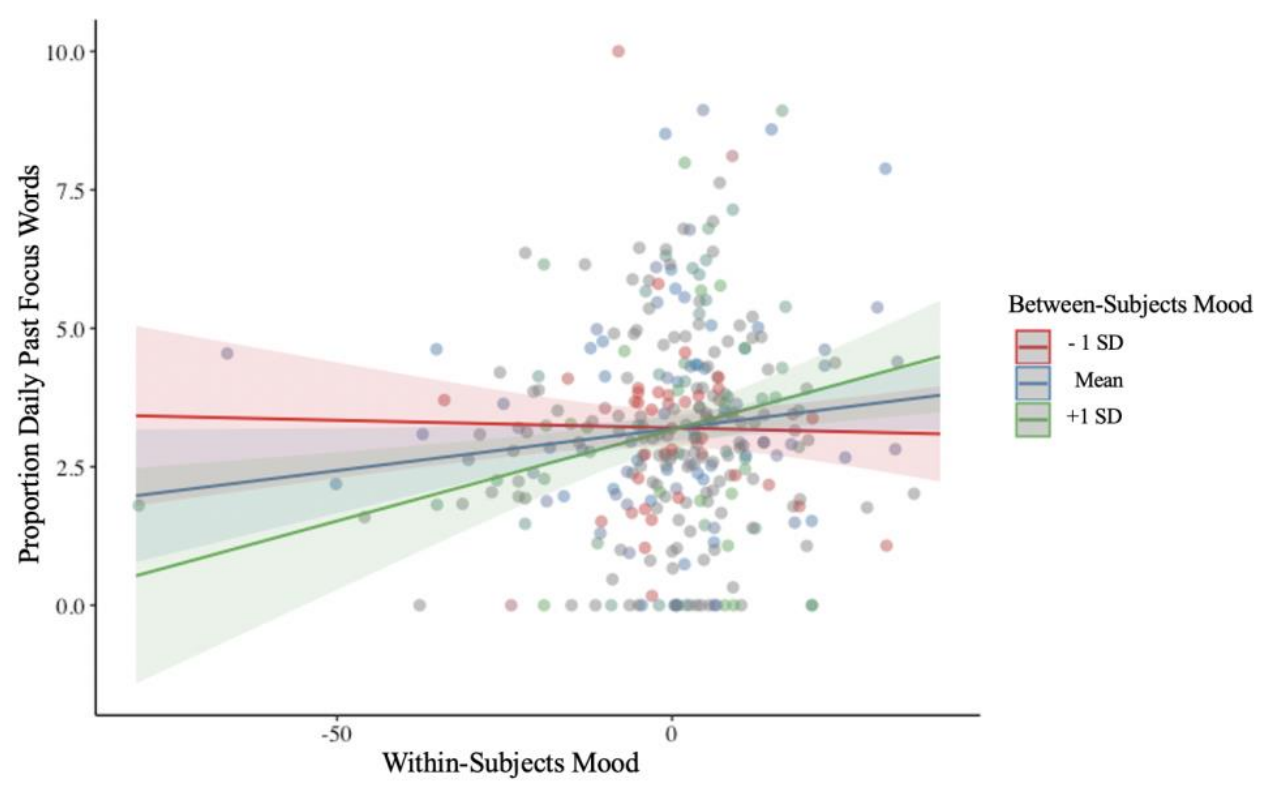

Figure 2. The scatterplot above shows the distribution of within-subjects mood along the $x$-axis and proportion of daily past focus words on the y-axis. Red, blue, and green lines represent the interactions of low, average and high levels of between-subjects mood, respectively, and within-subjects mood on past focus words. The shaded regions represents $95 \%$ confidence intervals. Between-subjects mood moderates the association between within-subjects mood and the proportion of daily past focus words.

\section{Present Focus Words}

Between-subjects mood was associated with present focus words $\left[\chi^{2}(1)=5.26, p=.029\right]$. Higher between-subjects mood was associated with lower daily proportion of present focus words $(\beta=-.21,95 \%$ CI [-.39, -.04]). Hierarchical model comparisons revealed that the simpler model with between-subjects mood only was the best fit model, and that adding within-subjects mood to the model did not improve the model fit $\left[\chi^{2}(1)=1.23, \mathrm{p}=.27\right]$. We did not observe a 


\section{ADOLESCENT SOCIAL COMMUNICATION}

main effect of depression or anxiety symptoms on present focus words, and neither depression nor anxiety symptoms nor age improved the model fit. These results suggest that higher mood between individuals is generally associated with a lower daily proportion of present focus words.

\section{Future Focus Words}

Between-subjects mood was associated with future focus words $\left[\chi^{2}(1)=8.73, p<.01\right]$. Lower between-subjects mood was associated with higher daily proportion of future focus words ( $\beta=-.27,95 \%$ CI [-.44, -.10]; Figure 3A). Hierarchical model comparisons revealed that the simpler model with between-subjects mood only was the best fit model, and that adding withinsubjects mood to the model did not improve the model fit $\left[\chi^{2}(1)=1.43, p=.23\right] .{ }^{1}$ In addition, depression symptoms were associated with future focus words $\left[\chi^{2}(1)=7.37, p<.01\right.$, Figure 3B]. Participants with higher depression symptoms tended to use more future focus words $(\beta=.25$, 95\% CI [.12,.39]). This effect remained when included in the model with between-subjects $\operatorname{mood}(\beta=.19,95 \%$ CI $[.04, .33])$. Hierarchical model comparisons revealed that the model with between-subjects mood and depression symptoms was the best fit with the lowest AIC compared to the simpler model with only depression symptoms $\left[\chi^{2}(1)=6.14, p=.01\right]$. We did not observe a main effect of anxiety, and neither anxiety symptoms nor age improved the model fit. Taken together, these results suggest that lower mood and higher depression symptoms are generally associated with a higher daily proportion of future focus words.

\footnotetext{
${ }^{1}$ There was a significant interaction between within- and between-subjects mood prior to the removal of one observation that was a multivariate outlier - a participant with an above-average between-subjects mood on a day with very low within-subjects mood used a very high proportion of future focus words on that day. Nonetheless, the association between extremely low within-subjects mood for individuals who typically demonstrate high betweensubjects mood and future focus words is an area for future research to explore.
} 
A.

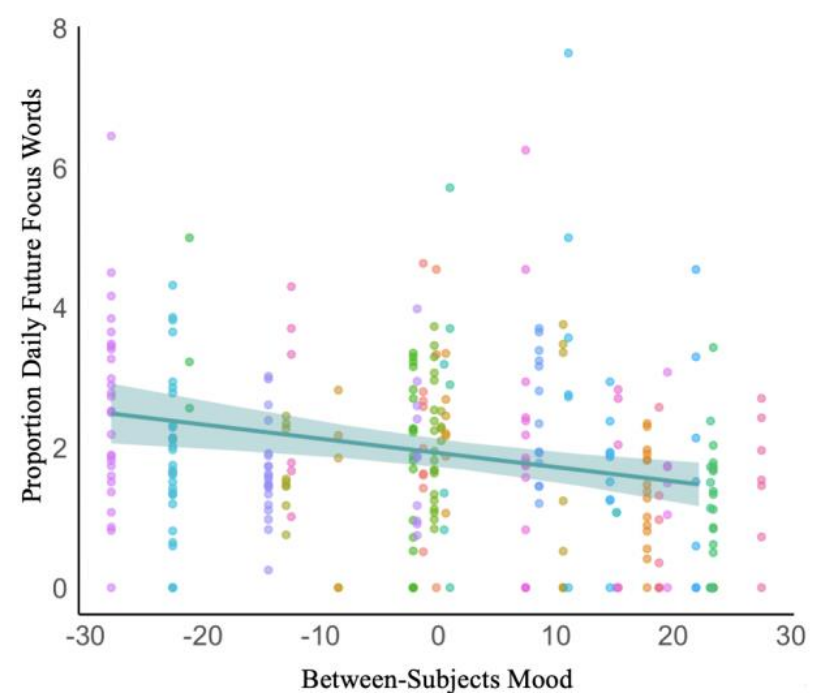

B.

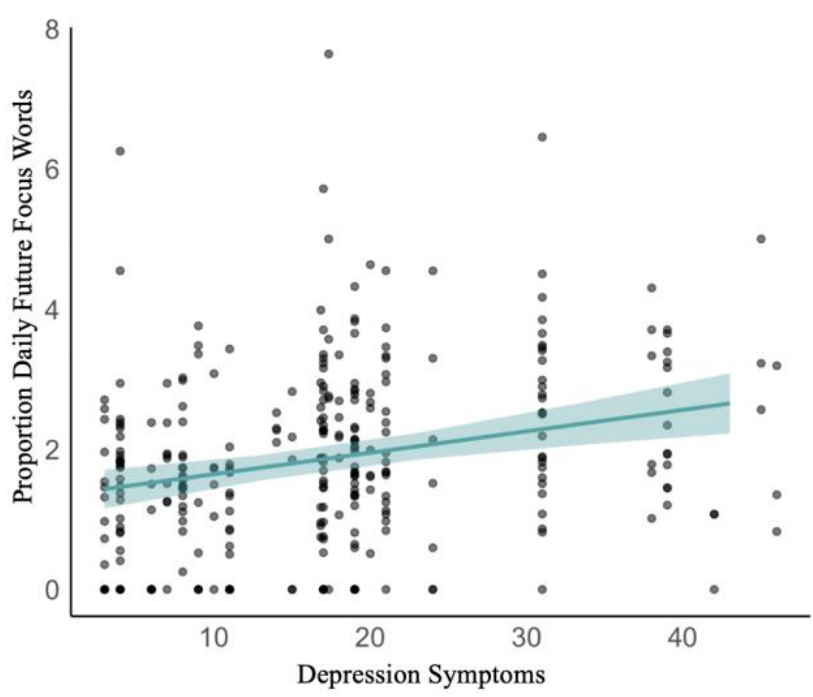

Figure 3. The scatterplots above depict the distribution of (A) between-subjects mood and proportion of daily future focus words and (B) depression symptoms and proportion of daily future focus words. The solid line represents the predicted regression line of this association, and the shaded region represents the $95 \%$ confidence interval. Lower between-subjects mood (grand mean centered) was associated with higher proportion of daily future focus words (A). Higher depression symptoms were associated with higher proportion of daily future focus words (B).

\section{Word Count}

Between-subjects mood moderated the association between within-subjects mood and daily word count $\left[\chi^{2}(3)=9.72, p=.02\right]$. Participants with lower-than-average mood tended to use more words on days when they experienced lower mood relative to their individual average $(\beta=.13,95 \%$ CI $[.03, .22])$. Individuals with lower-than-average mood texted fewer words on days when they reported more positive moods. Hierarchical model comparisons revealed that including the cross-level interaction of within- and between-subjects mood improved the model fit more than a simpler model of main effects $\left[\chi^{2}(1)=6.51, p=.01\right]$. Including age also improved the model fit $\left(\left[\chi^{2}(1)=4.44, p=.035\right]\right.$; Table 3$)$, indicating that older participants used more words on a daily basis $(\beta=.22,95 \% \mathrm{CI}[.01, .43])$. We did not observe a main effect of depression or anxiety symptoms on word count, and neither depression nor anxiety symptoms improved the model fit.

\section{Discussion}




\section{ADOLESCENT SOCIAL COMMUNICATION}

In this one-month, intensive longitudinal study, we investigated the extent to which linguistic features of digital social communication were linked to internalizing symptoms and daily mood in early adolescent girls. With this study design, we were able to disaggregate the association of 1) between-subject differences in depression and anxiety symptoms and average mood, and 2) within-subject variation in daily mood states, and language use in adolescence. Only one study has used a comparable between- and within-subject study design, measuring linguistic features from text messages during high-risk periods for suicide attempts (Glenn et al., 2020). This study found support for within-subject changes over time in linguistic features relating to higher risk for a suicide attempt; however, this study was in a high-risk sample of young adults. We analyzed daily communication solely from smartphone apps that are classified as social in nature and are therefore designed primarily for interpersonal communication. In particular, we were interested in linguistic features associated with social engagement (i.e., daily word count), self-focused attention (i.e., first-person pronouns), temporal characteristics (i.e., past, present, and future focus words), and sentiment (i.e., negative and positive emotion words).

Related to our first confirmatory hypothesis, we did not observe a significant association between depression symptoms and the use of first-person pronouns on a daily basis. This finding is in contrast to previous research (Edwards \& Holtzman, 2017) demonstrating this effect may not hold in a naturalistic social context and in an early adolescent sample. Interestingly, however, within-subjects mood was associated with the proportion of first-person pronoun use.

Participants tended to use more first-person pronouns on days when they experienced more negative mood compared to their average. In fact, the effect of within-subjects mood held when depression symptoms were included in the model, indicating that changes in first-person pronoun use is more closely linked to daily shifts in mood, rather than a depressive state. These results may indicate that girls experience an inward, self-focused attention when experiencing more negative mood that is revealed through pronoun use during interpersonal communication.

Related to our second hypothesis, we did not observe a significant association between depression symptoms and the use of negative emotion words. However, the direction of the effects is worth noting for the purpose of generating future hypotheses, particularly given the dearth of studies that have investigated these associations in naturalistic contexts. The effect of depression and anxiety symptoms were in the hypothesized direction; thus, future research could benefit from investigating this association in larger samples. Higher depression symptoms were 


\section{ADOLESCENT SOCIAL COMMUNICATION}

not robustly associated with the relative use of negative emotion words, which is in contrast to previous research on this association in other contexts (Rude et al., 2004). Higher use of negative emotion words may not be specific to depression symptoms, as it has also been found to be associated with symptom dimensions of personality disorders (Molendijk et al., 2010). At the other end of the spectrum, neither depression nor anxiety symptoms were not robustly associated with positive emotion words. However, between-subjects mood demonstrated a positive association with positive emotion words, indicating that use of positive emotion words may be linked more closely to overall positive affect. Nonetheless, daily fluctuations in mood were not associated with daily changes in the sentiment of social communication. Adolescence is a time of emotional variability (Larson \& Brown, 2007; Larson \& Sheeber, 2008) and as such, it may be very common for adolescents to use both positive and negative sentiment throughout their daily communication. Variability in oscillating between positive and negative sentiment in messages may most often occur within a given day for adolescents, similar to the daily fluctuations in emotions characteristic of adolescence (Larson \& Brown, 2007; Larson \& Sheeber, 2008). While this study was not designed to address intraday associations, these results nonetheless provide a basis for future research to explore.

Related to our first and second confirmatory hypotheses, we did not observe a significant association between anxiety symptoms and daily proportions of first-person pronouns or negative emotion words. Previous research has found associations between anxiety and firstperson pronouns and negative emotion words (Brockmeyer et al., 2015; Sonnenschein et al., 2018), however, these studies observed associations during a single time point, and in different language contexts (i.e., online forums, essay prompt, clinical interview). It may be the case that anxiety symptoms do not impact daily fluctuations in these linguistic features, but rather to the average use of these linguistic features over time. Further, as is noted below in the discussion of study limitations, it is possible that our measurement of anxiety did not fully capture anxiety symptoms over the course of the study, as it was completed on the last day of the study and asked participants to rate the items based on how it describes them "now." Nonetheless, we cannot interpret our null results as evidence of no possible effect. Further research is necessary before concluding that there is indeed no effect between anxiety symptoms and these linguistic features. 


\section{ADOLESCENT SOCIAL COMMUNICATION}

Participants with lower average mood over the study period tended to enter more words into social apps on a daily basis when experiencing a low mood day relative to their average day. Given that this is the case for participants who typically have low mood, having a higher daily word count might indicate maladaptive communication when feeling distressed, though the true nature of this association is difficult to detect. Indeed, various psychological phenomena could lead to or subsequently be affected by increased word count. For instance, an increase in word count for some adolescents may represent seeking help by reaching out to their social network when feeling low, which would be considered an adaptive behavior. However, for others, an increase in word count may represent a negative outcome of co-rumination, which is the extensive recounting of negative experiences and emotions within social relationships (Rose, 2002). Further, there are many remaining questions regarding the inverse relationship between mood and word count, such as whether increased word count indicates an increase in the quantity of people communicated with in a given day, or simply an increase in the quantity of words sent to an individual's typical number of daily contacts. Network size may moderate whether an individual's word count tends to be dispersed across a smaller or larger number of contacts when experiencing low mood, which may shed light on coping strategies and access to support when in a low mood. While previous research would suggest that individuals with lower mood may have smaller networks, and thus fewer people to contact, social integration and mood are more likely influenced by a sense of belonging in one's network (Ueno, 2005). Understanding the size of participants' networks is presently a challenging area to address, as the current data collection tool is not able to distinguish which messages are being sent to distinct individual recipients. Future technological development in data collection could pursue the distinguishing of unique recipients in a confidential manner that removes any identifying information, and simply reports which messages were sent to a distinct contact. Identifying distinct recipients of messages would better enable the detection of co-rumination patterns by linking the presence of contacts with a disproportionate quantity of words and changes in mood. Additionally, it is necessary to look at temporal associations and longitudinal patterns over time in order to understand the function of word use in conjunction with mood, such as whether increased word use is part of a maladaptive response (e.g., co-rumination) or compensatory behavior (e.g., reaching out for social support). Future longitudinal research could examine whether behavioral responses, such as these, mediate the use of more words on low mood days and increases or decreases in subsequent mood. 


\section{ADOLESCENT SOCIAL COMMUNICATION}

Participants with lower average mood compared to the sample average tended to use more present focus words. Greater use of present focus words have been found to be a component of decreased psychological distancing, which results in feeling psychologically proximal to one's distress. This finding contributes to existing research on the role of psychological distancing in effective emotion regulation (Nook et al., 2017) by demonstrating this effect in a novel naturalistic social context. While the link between greater present focus and lower mood appears to contrast with the present-focus awareness of mindfulness techniques of emotion regulation, using more present focus words in the context of social communication may actually represent the secondary processing of the present moment, which is counter to the tenets of mindfulness - a non-reactive and non-judgmental acceptance of the present experience (Brown et al., 2007; Chambers et al., 2009).

Participants with lower average mood and higher depression symptoms used more future focus words. Given that this was true at a between-subjects level, it appears that higher future focus words may be related to chronic, as opposed to acute, psychological distress, but further research is required to know whether future focus words indicate future worry and rumination, or perhaps are attempts to gain psychological distance (Bruehlman-Senecal \& Ayduk, 2015; Nook et al., 2017). Longitudinal research with a larger sample could explore whether using more future focus words on low mood days prospectively predicts increases or decreases in mood outcomes.

Taken together, we primarily found robust associations between within- and betweensubjects mood and our linguistic features of interest. Depression and anxiety symptoms, however, did not appear to be robustly associated with these linguistic features, with the sole exception of depression symptoms being associated with more future focus words. Further, relative model fit was not improved when adding measures of anxiety and depression to models that included mood, again, with the exception of depression symptoms and future focus words.

Given that participants ranged in age from 11 to 15 , spanning grades 6 to 10 , we tested age in all of our final, most complex hierarchical models to assess for improved model fit. We did not have an a priori hypothesis regarding the association of age with our linguistic features, so these were exploratory analyses. Nonetheless, given the lack of previous research in this domain, we deemed it worth noting these effects to support future developmental studies in this area. Interestingly, age appeared to have an association with two linguistic features of interest daily word count and past focus words. In both cases, older participants communicated with 


\section{ADOLESCENT SOCIAL COMMUNICATION}

more words on a daily basis and utilized relatively more past focus words. We cannot distinguish through these data whether the daily use of more words represents a positive outcome such as greater social connection, or a negative outcome such as greater co-rumination. While this effect is consistent with previous research that found that adolescents send more text messages as they progress from their freshman to junior years in high school (Ehrenreich et al., 2019), it is unclear if the greater frequency of text messages in this previous study translated directly to a greater number of words. We did not have an a priori reason to examine the interaction between age and mood on linguistic features, however this is an area that future research could explore. Additionally, future longitudinal research of a longer duration could potentially assess the trajectories of these features across time in conjunction with increasing age. Further, pubertal timing is a developmental process highly associated with, but nonetheless distinct from, age and may in part account for the age-related variability. Given the links between pubertal timing and internalizing symptoms during adolescence (Hamlat et al., 2019; Ullsperger \& Nikolas, 2017), and the potential mediating role of social relationships (Conley et al., 2012), pubertal processes are a prime area for future research related to social communication and mental health.

This study had both methodological strengths and limitations. The age of the sample, the longitudinal measurement of language and mood, along with the highly salient and naturalistic social context, make this a novel study. However, it is a limitation that given the lack of comparable studies we were unable to rely on our null results as evidence of the absence of an effect. Without an estimate of a meaningful effect size for the linguistic features from previous studies, we could not draw firm conclusions about our null results, particularly relating to depression and anxiety symptoms. Additionally, our measurement of anxiety symptoms was not definitively retrospective. The anxiety questionnaire was completed on the last day of the study and asked participants to rate how each item describes them "now", so we do not know precisely what timeframe each participant is considering when they are assessing their own symptoms, and whether those symptoms were indeed present during the previous month of message data collection. This was not the case for depression symptoms, however, as the CES-DC measure is indeed a retrospective report. Additionally, it is a limitation that we are not able to distinguish between private direct messages and public social media posts; thus, we cannot definitively know that every message was sent to a known personal contact. Further, we have a relatively small sample size due to enrollment being paused during the COVID-19 pandemic and as such, 


\section{ADOLESCENT SOCIAL COMMUNICATION}

we have insufficient power to test interactions between mental health and within-subjects mood. Although prior work has recommended that general rules of thumb about sample size (i.e., minimum of $n=30$ ) do not necessarily apply when using MLM to estimate cross-level interaction effects (Aguinis et al., 2013), we nonetheless used REML to reduce bias (Luke, 2017; McNeish, 2017), an acknowledge that our Level-2 sample size of 30 renders our between-person findings to be more formative in nature, as opposed to summative. Additionally, given the variability in participant compliance in completing daily EMAs, combined with the presence of gaps in text data due to technical issues, it is possible that the data may not have been missing at random. For instance, participants may have been less likely to complete the EMA on days with particularly low mood. Participants were advised to answer promptly at $8 \mathrm{am}$ and in relation to the previous day; however, it is also a limitation that our EMA questionnaire could be answered within a wide timeframe.

The present study provides a longitudinal, concurrent assessment of daily mood with daily digital communication, which allowed for testing changes in mood with changes in naturalistic social language. Our findings support the conclusion that both between-subject individual differences and within-subject fluctuations in mood are associated with certain linguistic features of daily social communication. We have found evidence that the quantity of communication, along with features related to self-focused attention, and psychological distancing may be reflective of lower mood, and depression symptoms may be reflected in the use of future-oriented words. Lastly, it is theoretically likely that language and mental states interact and have a bidirectional relationship, especially in the context of smartphones, but more research is required to elucidate this theory. Future research can begin to test such lagged effects, in addition to the construct validity of these linguistic features, particularly for adolescents, as many questions remain regarding the function of these features and what underlying psychological processes drive their use, or are affected by their use. Nonetheless, this study contributes to a better understanding of linguistic markers of mood in adolescents, which provides a direction for future research that may ultimately inform preventative interventions for adolescent mental health.

\section{Author Contributions}




\section{ADOLESCENT SOCIAL COMMUNICATION}

E.A. McNeilly, K.L. Mills, N.B. Allen, and J.H. Pfeifer designed the research. E.A. McNeilly analyzed the data and drafted the manuscript. K.L. Mills, L.E. Kahn, and R. Crowley contributed to data collection, and provided statistical consultation. K.L. Mills, J.H. Pfeifer, and N.B. Allen provided critical comments and revisions. All of the authors approved the final manuscript for submission. 


\section{ADOLESCENT SOCIAL COMMUNICATION}

\section{References}

Aguinis, H., Gottfredson, R. K., \& Culpepper, S. A. (2013). Best-Practice Recommendations for Estimating Cross-Level Interaction Effects Using Multilevel Modeling. Journal of Management, 39(6), 1490-1528. https://doi.org/10.1177/0149206313478188

Al-Mosaiwi, M., \& Johnstone, T. (2018). In an Absolute State: Elevated Use of Absolutist Words Is a Marker Specific to Anxiety, Depression, and Suicidal Ideation. Clinical Psychological Science, 6(4), 529-542. https://doi.org/10.1177/2167702617747074

Barendse, M. E. A., Vijayakumar, N., Byrne, M. L., Flannery, J. E., Cheng, T. W., Flournoy, J. C., Nelson, B. W., Cosme, D., Mobasser, A., Chavez, S. J., Hval, L., Brady, B., Nadel, H., Helzer, A., Shirtcliff, E. A., Allen, N. B., \& Pfeifer, J. H. (2020). Study Protocol: Transitions in Adolescent Girls (TAG). Frontiers in Psychiatry, 10. https://doi.org/10.3389/fpsyt.2019.01018

Bates, D., Mächler, M., Bolker, B., \& Walker, S. (2015). Fitting Linear Mixed-Effects Models Using lme4. Journal of Statistical Software, 67(1). https://doi.org/10.18637/jss.v067.i01

Bernard, J. D., Baddeley, J. L., Rodriguez, B. F., \& Burke, P. A. (2016). Depression, Language, and Affect: An Examination of the Influence of Baseline Depression and Affect Induction on Language. Journal of Language and Social Psychology, 35(3), 317-326. https://doi.org/10.1177/0261927X15589186

Birmaher, B., Brent, D. A., Chiappetta, L., Bridge, J., Monga, S., \& Baugher, M. (1999). Psychometric Properties of the Screen for Child Anxiety Related Emotional Disorders (SCARED): A Replication Study. Journal of the American Academy of Child \& Adolescent Psychiatry, 38(10), 1230-1236. https://doi.org/10.1097/00004583199910000-00011 


\section{ADOLESCENT SOCIAL COMMUNICATION}

Bono, C., Ried, L. D., Kimberlin, C., \& Vogel, B. (2007). Missing data on the Center for Epidemiologic Studies Depression Scale: A comparison of 4 imputation techniques. Research in Social and Administrative Pharmacy, 3(1), 1-27. https://doi.org/10.1016/j.sapharm.2006.04.001

Brockmeyer, T., Zimmermann, J., Kulessa, D., Hautzinger, M., Bents, H., Friederich, H.-C., Herzog, W., \& Backenstrass, M. (2015). Me, myself, and I: Self-referent word use as an indicator of self-focused attention in relation to depression and anxiety. Frontiers in Psychology, 6. https://doi.org/10.3389/fpsyg.2015.01564

Brown, K. W., Ryan, R. M., \& Creswell, J. D. (2007). Mindfulness: Theoretical Foundations and Evidence for its Salutary Effects. Psychological Inquiry, 18(4), 211-237. https://doi.org/10.1080/10478400701598298

Bruehlman-Senecal, E., \& Ayduk, O. (2015). This too shall pass: Temporal distance and the regulation of emotional distress. Journal of Personality and Social Psychology, 108(2), 356-375. https://doi.org/10.1037/a0038324

Chambers, R., Gullone, E., \& Allen, N. B. (2009). Mindful emotion regulation: An integrative review. Clinical Psychology Review, 29(6), 560-572. https://doi.org/10.1016/j.cpr.2009.06.005

Conley, C. S., Rudolph, K. D., \& Bryant, F. B. (2012). Explaining the longitudinal association between puberty and depression: Sex differences in the mediating effects of peer stress. Development and Psychopathology, 24(2), 691-701. https://doi.org/10.1017/S0954579412000259 


\section{ADOLESCENT SOCIAL COMMUNICATION}

Crone, E. A., \& Dahl, R. E. (2012). Understanding adolescence as a period of social-affective engagement and goal flexibility. Nature Reviews Neuroscience, 13(9), 636-650. https://doi.org/10.1038/nrn3313

Dahl, R. E., Allen, N. B., Wilbrecht, L., \& Suleiman, A. B. (2018). Importance of investing in adolescence from a developmental science perspective. Nature, 554(7693), 441-450. https://doi.org/10.1038/nature25770

Edwards, T., \& Holtzman, N. S. (2017). A meta-analysis of correlations between depression and first person singular pronoun use. Journal of Research in Personality, 68, 63-68. https://doi.org/10.1016/j.jrp.2017.02.005

Ehrenreich, S. E., Beron, K. J., Burnell, K., Meter, D. J., \& Underwood, M. K. (2019). How Adolescents Use Text Messaging Through their High School Years. Journal of Research on Adolescence, jora.12541. https://doi.org/10.1111/jora.12541

Eichstaedt, J. C., Smith, R. J., Merchant, R. M., Ungar, L. H., Crutchley, P., Preoţiuc-Pietro, D., Asch, D. A., \& Schwartz, H. A. (2018). Facebook language predicts depression in medical records. Proceedings of the National Academy of Sciences, 115(44), 1120311208. https://doi.org/10.1073/pnas.1802331115

Enders, C. K., \& Tofighi, D. (2007). Centering predictor variables in cross-sectional multilevel models: A new look at an old issue. Psychological Methods, 12(2), 121-138. https://doi.org/10.1037/1082-989X.12.2.121

Everaert, J., Bronstein, M. V., Cannon, T. D., \& Joormann, J. (2018). Looking Through Tinted Glasses: Depression and Social Anxiety Are Related to Both Interpretation Biases and Inflexible Negative Interpretations. Clinical Psychological Science, 6(4), 517-528. https://doi.org/10.1177/2167702617747968 


\section{ADOLESCENT SOCIAL COMMUNICATION}

Faulstich, M. E., Carey, M. P., Ruggiero, L., Enyart, P., \& Gresham, F. (1986). Assessment of depression in childhood and adolescence: An evaluation of the Center for Epidemiological Studies Depression Scale for Children (CES-DC). American Journal of Psychiatry, 143(8), 1024-1027. https://doi.org/10.1176/ajp.143.8.1024

Glenn, J. J., Nobles, A. L., Barnes, L. E., \& Teachman, B. A. (2020). Can Text Messages Identify Suicide Risk in Real Time? A Within-Subjects Pilot Examination of Temporally Sensitive Markers of Suicide Risk. Clinical Psychological Science, 8(4), 704-722. https://doi.org/10.1177/2167702620906146

Gross, J. J., \& Jazaieri, H. (2014). Emotion, Emotion Regulation, and Psychopathology: An Affective Science Perspective. Clinical Psychological Science, 2(4), 387-401. https://doi.org/10.1177/2167702614536164

Haaga, D. A. F., \& Beck, A. T. (1995). Perspectives on depressive realism: Implications for cognitive theory of depression. Behaviour Research and Therapy, 33(1), 41-48. https://doi.org/10.1016/0005-7967(94)E0016-C

Hamilton, E. W., \& Abramson, L. Y. (1983). Cognitive patterns and major depressive disorder: A longitudinal study in a hospital setting. Journal of Abnormal Psychology, 92(2), 173. https://doi.org/10.1037/0021-843X.92.2.173

Hamlat, E. J., Snyder, H. R., Young, J. F., \& Hankin, B. L. (2019). Pubertal Timing as a Transdiagnostic Risk for Psychopathology in Youth. Clinical Psychological Science, 7(3), 411-429. https://doi.org/10.1177/2167702618810518

Hankin, B. L., \& Abramson, L. Y. (2001). Development of Gender Differences in Depression: An Elaborated Cognitive Vulnerability-Transactional Stress Theory. Psychological Bulletin, 127(6), 773-796. https://doi.org/10.1037//O033-29O9.127.6.773 


\section{ADOLESCENT SOCIAL COMMUNICATION}

Hayati Rezvan, P., Lee, K. J., \& Simpson, J. A. (2015). The rise of multiple imputation: A review of the reporting and implementation of the method in medical research. $B M C$ Medical Research Methodology, 15(1), 30. https://doi.org/10.1186/s12874-015-0022-1

Hofmann, S. G., Sawyer, A. T., Fang, A., \& Asnaani, A. (2012). Emotion dysregulation model of mood and anxiety disorders. Depression and Anxiety, 29(5), 409-416. https://doi.org/10.1002/da.21888

Kessler, R. C., Berglund, P., Demler, O., Jin, R., Koretz, D., Merikangas, K. R., Rush, A. J., Walters, E. E., \& Wang, P. S. (2003). The Epidemiology of Major Depressive Disorder: Results From the National Comorbidity Survey Replication (NCS-R). JAMA, 289(23), 3095-3105. https://doi.org/10.1001/jama.289.23.3095

Kessler, R. C., \& Wang, P. S. (2008). The Descriptive Epidemiology of Commonly Occurring Mental Disorders in the United States. Annual Review of Public Health, 29(1), 115-129. https://doi.org/10.1146/annurev.publhealth.29.020907.090847

Kross, E., Verduyn, P., Boyer, M., Drake, B., Gainsburg, I., Vickers, B., Ybarra, O., \& Jonides, J. (2019). Does counting emotion words on online social networks provide a window into people's subjective experience of emotion? A case study on Facebook. Emotion, 19(1), 97-107. https://doi.org/10.1037/emo0000416

Larson, R. W., \& Brown, J. R. (2007). Emotional Development in Adolescence: What Can Be Learned from a High School Theater Program? Child Development, 78(4), 1083-1099.

Larson, R. W., \& Sheeber, L. B. (2008). The daily emotional experience of adolescents: Are adolescents more emotional, why, and how is that related to depression? In L. B. Sheeber \& N. B. Allen (Eds.), Adolescent Emotional Development and the Emergence of 


\section{ADOLESCENT SOCIAL COMMUNICATION}

Depressive Disorders (pp. 11-32). Cambridge University Press. https://doi.org/10.1017/CBO9780511551963.002

Lee, K. J., \& Simpson, J. A. (2014). Introduction to multiple imputation for dealing with missing data. Respirology, 19(2), 162-167. https://doi.org/10.1111/resp.12226

Lind, M. N., Byrne, M. L., Wicks, G., Smidt, A. M., \& Allen, N. B. (2018). The Effortless Assessment of Risk States (EARS) Tool: An Interpersonal Approach to Mobile Sensing. JMIR Mental Health, 5(3). https://doi.org/10.2196/10334

Luke, S. G. (2017). Evaluating significance in linear mixed-effects models in R. Behavior Research Methods, 49(4), 1494-1502. https://doi.org/10.3758/s13428-016-0809-y

McNeish, D. (2017). Small Sample Methods for Multilevel Modeling: A Colloquial Elucidation of REML and the Kenward-Roger Correction. Multivariate Behavioral Research, 52(5), 661-670. https://doi.org/10.1080/00273171.2017.1344538

Molendijk, M. L., Bamelis, L., van Emmerik, A. A. P., Arntz, A., Haringsma, R., \& Spinhoven, P. (2010). Word use of outpatients with a personality disorder and concurrent or previous major depressive disorder. Behaviour Research and Therapy, 48(1), 44-51. https://doi.org/10.1016/j.brat.2009.09.007

Mor, N., \& Winquist, J. (2002). Self-focused attention and negative affect: A meta-analysis. Psychological Bulletin, 128(4), 638-662. https://doi.org/10.1037/0033-2909.128.4.638

Moreno, M. A., Binger, K., Zhao, Q., \& Eickhoff, J. (2020). Measuring Interests Not Minutes: Development and Validation of the Adolescents' Digital Technology Interactions and Importance Scale (ADTI). Journal of Medical Internet Research, 22(2), e16736. https://doi.org/10.2196/16736 


\section{ADOLESCENT SOCIAL COMMUNICATION}

Muris, P., Merckelbach, H., Schmidt, H., \& Mayer, B. (1998). The revised version of the Screen for Child Anxiety Related Emotional Disorders (SCARED-R): Factor structure in normal children. Personality and Individual Differences, 26(1), 99-112. https://doi.org/10.1016/S0191-8869(98)00130-5

Nelson, E. E., Jarcho, J. M., \& Guyer, A. E. (2016). Social re-orientation and brain development: An expanded and updated view. Developmental Cognitive Neuroscience, 17, 118-127. https://doi.org/10.1016/j.dcn.2015.12.008

Nook, E. C., Schleider, J. L., \& Somerville, L. H. (2017). A linguistic signature of psychological distancing in emotion regulation. Journal of Experimental Psychology: General, 146(3), 337-346. https://doi.org/10.1037/xge0000263

Nook, E. C., Vidal Bustamante, C. M., Cho, H. Y., \& Somerville, L. H. (2019). Use of linguistic distancing and cognitive reappraisal strategies during emotion regulation in children, adolescents, and young adults. Emotion. https://doi.org/10.1037/emo0000570

O’Dea, B., Larsen, M. E., Batterham, P. J., Calear, A. L., \& Christensen, H. (2017). A Linguistic Analysis of Suicide-Related Twitter Posts. Crisis: The Journal of Crisis Intervention and Suicide Prevention, 38(5), 319-329. https://doi.org/10.1027/0227-5910/a000443

Odgers, C. L., \& Jensen, M. R. (2020). Annual Research Review: Adolescent mental health in the digital age: facts, fears, and future directions. Journal of Child Psychology and Psychiatry, 61(3), 336-348. https://doi.org/10.1111/jcpp.13190

Orben, A., Przybylski, A. K., Blakemore, S.-J., \& Kievit, R. A. (2022). Windows of developmental sensitivity to social media. Nature Communications, 13(1), 1649. https://doi.org/10.1038/s41467-022-29296-3

Orvell, A., Vickers, B. D., Drake, B., Verduyn, P., Ayduk, O., Moser, J., Jonides, J., \& Kross, E. 


\section{ADOLESCENT SOCIAL COMMUNICATION}

(2021). Does Distanced Self-Talk Facilitate Emotion Regulation Across a Range of Emotionally Intense Experiences? Clinical Psychological Science, 9(1), 68-78. https://doi.org/10.1177/2167702620951539

Pavalanathan, U., \& De Choudhury, M. (2015). Identity Management and Mental Health Discourse in Social Media. Proceedings of the ... International World-Wide Web Conference. International WWW Conference, 2015(Companion), 315-321.

Pennebaker, J. W., Boyd, R. L., Jordan, K., \& Blackburn, K. (2015). The Development and Psychometric Properties of LIWC2015. Austin, TX: University of Texas at Austin, 26.

Peugh, J. L. (2010). A practical guide to multilevel modeling. Journal of School Psychology, 48(1), 85-112. https://doi.org/10.1016/j.jsp.2009.09.002

Pew Research Center. (2018). Teens, Social Media \& Technology 2018.

R Core Team. (2019). R: The R Project for Statistical Computing. R Foundation for Statistical Computing. https://www.r-project.org/

Ramirez-Esparza, N., Chung, C. K., Kacewicz, E., \& Pennebaker, J. W. (2008). The Psychology of Word Use in Depression Forums in English and in Spanish: Testing Two Text Analytic Approaches. Association for the Advancement of Artificial Intelligence, 7.

Rideout, V., \& Robb, M. B. (2018). Social Media, Social Life: Teens Reveal Their Experiences. San Francisco, CA: Common Sense Media.

Rodman, A. M., Vidal Bustamante, C. M., Dennison, M. J., Flournoy, J. C., Coppersmith, D. D. L., Nook, E. C., Worthington, S., Mair, P., \& McLaughlin, K. A. (2021). A Year in the Social Life of a Teenager: Within-Persons Fluctuations in Stress, Phone Communication, and Anxiety and Depression. Clinical Psychological Science, 2167702621991804. https://doi.org/10.1177/2167702621991804 


\section{ADOLESCENT SOCIAL COMMUNICATION}

Rose, A. J. (2002). Co-Rumination in the Friendships of Girls and Boys. Child Development, 73(6), 1830-1843. https://doi.org/10.1111/1467-8624.00509

Rose, A. J., \& Rudolph, K. D. (2006). A review of sex differences in peer relationship processes: Potential trade-offs for the emotional and behavioral development of girls and boys. Psychological Bulletin, 132(1), 98-131. https://doi.org/10.1037/0033-2909.132.1.98

Rude, S., Gortner, E.-M., \& Pennebaker, J. (2004). Language use of depressed and depressionvulnerable college students. Cognition and Emotion, 18(8), 1121-1133. https://doi.org/10.1080/02699930441000030

Rudolph, K. D., \& Hammen, C. (1999). Age and Gender as Determinants of Stress Exposure, Generation, and Reactions in Youngsters: A Transactional Perspective. Child Development, 70(3), 660-677. https://doi.org/10.1111/1467-8624.00048

Singer, J. D., \& Willett, J. B. (2003). Applied longitudinal data analysis: Modeling change and event occurrence (pp. xx, 644). Oxford University Press. https://doi.org/10.1093/acprof:oso/9780195152968.001.0001

Somerville, L. H. (2013). The Teenage Brain: Sensitivity to Social Evaluation. Current Directions in Psychological Science, 22(2), 121-127. https://doi.org/10.1177/0963721413476512

Sonnenschein, A. R., Hofmann, S. G., Ziegelmayer, T., \& Lutz, W. (2018). Linguistic analysis of patients with mood and anxiety disorders during cognitive behavioral therapy. Cognitive Behaviour Therapy, 47(4), 315-327. https://doi.org/10.1080/16506073.2017.1419505

Spies Shapiro, L. A., \& Margolin, G. (2014). Growing Up Wired: Social Networking Sites and Adolescent Psychosocial Development. Clinical Child and Family Psychology Review, 17(1), 1-18. https://doi.org/10.1007/s10567-013-0135-1 


\section{ADOLESCENT SOCIAL COMMUNICATION}

Tackman, A. M., Sbarra, D. A., Carey, A. L., Donnellan, M. B., Horn, A. B., Holtzman, N. S., Edwards, T. S., Pennebaker, J. W., \& Mehl, M. R. (2019). Depression, Negative Emotionality, and Self-Referential Language: A Multi-Lab, Multi-Measure, and MultiLanguage-Task Research Synthesis. Journal of Personality and Social Psychology, $116(5), 817-834$.

Ueno, K. (2005). The effects of friendship networks on adolescent depressive symptoms. Social Science Research, 34(3), 484-510. https://doi.org/10.1016/j.ssresearch.2004.03.002

Ullsperger, J. M., \& Nikolas, M. A. (2017). A meta-analytic review of the association between pubertal timing and psychopathology in adolescence: Are there sex differences in risk? Psychological Bulletin, 143(9), 903-938. https://doi.org/10.1037/bul0000106

Underwood, M. K., Ehrenreich, S. E., More, D., Solis, J. S., \& Brinkley, D. Y. (2015). The BlackBerry Project: The Hidden World of Adolescents' Text Messaging and Relations With Internalizing Symptoms. Journal of Research on Adolescence (Wiley-Blackwell), 25(1), 101-117. https://doi.org/10.1111/jora.12101

van Buuren, S., \& Groothuis-Oudshoorn, K. (2011). mice: Multivariate Imputation by Chained Equations in R. Journal of Statistical Software, 45(1), 1-67. https://doi.org/10.18637/jss.v045.i03

Weissman, M. M., Orvaschel, H., \& Padian, N. (1980). Children’s Symptom and Social Functioning Self-Report Scales Comparison of Mothers' and Children's Reports. The Journal of Nervous and Mental Disease, 168(12), 736-740.

Zimmermann, J., Brockmeyer, T., Hunn, M., Schauenburg, H., \& Wolf, M. (2017). First-person Pronoun Use in Spoken Language as a Predictor of Future Depressive Symptoms: 


\section{ADOLESCENT SOCIAL COMMUNICATION}

Preliminary Evidence from a Clinical Sample of Depressed Patients. Clinical Psychology \& Psychotherapy, 24(2), 384-391. https://doi.org/10.1002/cpp.2006

Zimmermann, J., Wolf, M., Bock, A., Peham, D., \& Benecke, C. (2013). The way we refer to ourselves reflects how we relate to others: Associations between first-person pronoun use and interpersonal problems. Journal of Research in Personality, 47(3), 218-225.

https://doi.org/10.1016/j.jrp.2013.01.008 